\title{
SARS-CoV-2 plays a pivotal role in inducing hyperthyroidism of Graves' disease
}

\author{
Avaniyapuram Kannan Murugan $\mathbb{( i}^{1} \cdot$ Ali S. Alzahrani ${ }^{1,2}$
}

Received: 5 April 2021 / Accepted: 17 May 2021 / Published online: 9 June 2021

(c) The Author(s), under exclusive licence to Springer Science+Business Media, LLC, part of Springer Nature 2021

\begin{abstract}
Coronavirus disease 2019 (COVID-19) advances to affect every part of the globe and remains a challenge to the human race. Severe acute respiratory syndrome-coronavirus-2 (SARS-CoV-2) was shown to affect many organs and organ systems including the thyroid gland as these parts highly express angiotensin-converting enzyme 2 (ACE2) protein, which functions as a receptor for initially entering the virus into the cells. Furthermore, some categories of the population including older people and persons with comorbidities are prone to be more vulnerable to COVID-19 and its complications. Recent reports showed that SARS-CoV-2 infection could cause Graves' disease (autoimmune hyperthyroidism) in post-COVID-19 patients. Factors that may boost the mortality risk of COVID-19 patients are not completely known yet and a clear perception of the group of vulnerable people is also essential. This review briefly summarizes the features of Graves' disease such as symptoms, risk factors, including environmental, genetic, immunological, and other factors, associated disorders, and therapeutic options. It comprehensively describes the recent advances in SARS-CoV-2-induced Graves' disease and the pivotal role of autoimmune factors in inducing the disease. The review also discusses the possible risks of SARS-CoV-2 infection and associated COVID19 in people with hyperthyroidism. Furthermore, it explains thyroid disease and its association with the severity of COVID-19.
\end{abstract}

Keywords Thyroid $\cdot$ COVID-19 $\cdot$ Hyperthyroidism $\cdot$ Autoimmune $\cdot$ SARS-CoV-2 $\cdot$ Graves' disease $\cdot$ ACE2 $\cdot$ RAAS

\section{Abbreviations}

COVID-19 coronavirus disease 2019

SARS- severe acute respiratory

$\mathrm{CoV}-2$ syndrome-coronavirus-2

ACE2 angiotensin-converting enzyme 2

ILs interleukins

NICU non-intensive care unit

ATDs antithyroid drugs

ATA American Thyroid Association

AACE American Association of Clinical Endocrinology

TNF- $\alpha$ tumor necrosis factor- $\alpha$

Th1 T helper cell 1

Th2 T helper cell 2

AITD autoimmune thyroid disease

TCR $t$ cell receptor

RT-PCR real-time PCR

\section{Introduction}

The COVID-19 is a severe acute respiratory syndrome that is triggered by a sense-stranded RNA virus, SARS-CoV-2 [1]. Globally, this disease has emerged as a pandemic and as of May 11th, 2021, 159,727,874 people are affected and $3,319,141$ people have succumbed to this disease while the majority of them were from North America, Europe, and India although the outbreak began from China. The overall mortality rate of COVID-19 infected people ranges from $\sim 0.07-9.3 \%$ [2]. Moreover, both the infection and death rates are expected to proportionally increase further as the disease rapidly spreads across different continents, and failure to contain the virus may lead to more cataclysmic effects than expected.
Avaniyapuram Kannan Murugan

akmurugan@gmail.com

1 Division of Molecular Endocrinology, Department of Molecular Oncology, King Faisal Specialist Hospital and Research Centre, Riyadh 11211, Saudi Arabia
2 Department of Medicine, King Faisal Specialist Hospital and Research Centre, Riyadh 11211, Saudi Arabia 
Notably, patients with preexisting comorbidities were shown to have severe disease, which often results in death. Many vital organ-related comorbidities including diabetes mellitus, hypertension, heart disease, and chronic lung disease have been reported to be associated with COVID-19 related mortality. A recent work analyzed 1590 COVID-19 cases and found that the subjects with comorbidities displayed poorer clinical outcomes compared with the control group. The poor prognosis of COVID-19 was observed when older age was combined with severe disease [3].

The SARS-CoV-2 exploits ACE2 much like a receptor for its initial entry [1]. ACE2 expression was demonstrated to be higher in the epithelial cells of the lungs, heart, kidneys, blood vessels, small intestine, testes, adipose tissue, and the thyroid gland [4]. It is likely that the thyroid gets affected by the virus as thyroid cells ubiquitously express the ACE2 protein, the viral receptor (Fig. 1). A retrospective and single-center study evaluated thyroid functions and IL-6 levels in 287 COVID-19 cases admitted in non-intensive care units (NICU) and the results revealed that COVID-19 could significantly correlate with a high risk of thyrotoxicosis due to the systemic immune activation that is commonly induced by the SARS-CoV-2 viral infection [5]. Recent reports showed that SARS-CoV-2 could affect the thyroid gland and cause Graves' disease, an autoimmune hyperthyroidism in post-COVID-19 cases [6, 7].

\section{Graves' disease: basics in brief}

Thyroid hormones critically regulate cell metabolism, heart rate, body temperature, blood pressure, and many other vital physiological processes [8]. Graves' disease-an autoimmune disorder that affects thyroid, which is the foremost common explanation for hyperthyroidism. This affects mostly females than males in a 5-10:1 ratio and peaks in middle-age though it could affect lower age groups as well (children and adolescents). Although the overall prevalence of hyperthyroidism is $\sim 2-3 \%$ in the general population, it is rapidly increasing in women while the prevalence is $\sim 5 \%$ in older women. The hyperthyroidism condition is more commonly seen in smoking people. Among the different

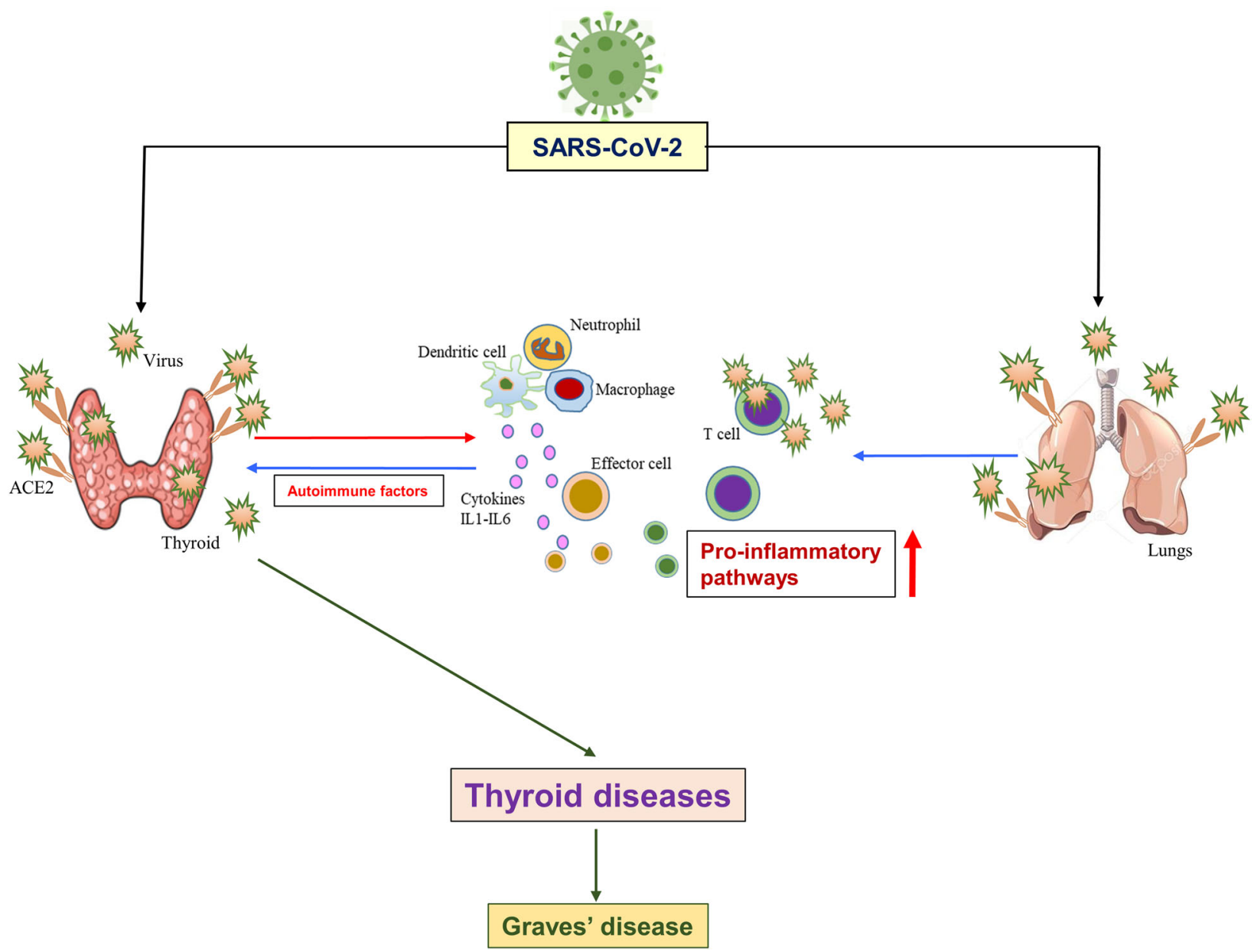

Fig. 1 SARS-CoV-2 and the thyroid gland. The schematic diagram shows the possible route of thyroid gland infection. Viral receptor protein, ACE2 is highly expressed in thyroid similar to other organs including the nasopharynx and lungs that facilitate a direct viral infection. Infection in other organs may also transmit the virus and/or the immune cells that in turn attack thyroid gland 
Table 1 Factors involved in Graves' disease (autoimmune hyperthyroidism)

\begin{tabular}{|c|c|c|c|}
\hline Environmental factors & $\begin{array}{l}\text { Genetic } \\
\text { factors }\end{array}$ & Immunological factors & Other factors \\
\hline $\begin{array}{l}\text { Cigarette smoking } \\
\text { Exposure to radiation } \\
\text { Direct exposure to ethanol (injection) } \\
\text { Immune-checkpoint inhibitors } \\
\text { treatment } \\
\text { Iodine } \\
\text { Therapeutic use of IL-1 } \alpha, \text { IL-2, IFN } \\
\alpha \text { and } \gamma \\
\text { Therapeutic use of HIV drugs } \\
\text { Therapeutic use of alemtuzumab }\end{array}$ & $\begin{array}{l}C T L A-4 \\
C D-40 \\
H L A \text { Class-II } \\
\text { TG gene } \\
\text { TSHR gene }\end{array}$ & $\begin{array}{l}\text { Activation of T cells by polyclonal stimuli } \\
\text { Cross-reacting epitopes on environmental and thyroid antigens } \\
\text { In appropriate } H L A-D R \text { expression } \\
\text { Inheritance of } H L A, C T L A-4 \text { and other immune } \\
\text { response genes } \\
\text { Mutated T or B cell clones } \\
\text { Persistence of some autoreactive T cells and B cells } \\
\text { Stimulation of the thyroid by cytokines } \\
\text { Re-exposure of antigens by thyroid cell damage } \\
\text { Reduced or dysfunctional regulatory T cells }\end{array}$ & $\begin{array}{l}\text { Female gender } \\
\text { Psychic trauma } \\
\text { Sympathetic } \\
\text { hyperactivity } \\
\text { TSH } \\
\text { Weight loss }\end{array}$ \\
\hline
\end{tabular}

$I L$ interleukin, $I F N$ interferon, $H I V$ human immunodeficiency virus, CTLA-4 cytotoxic T-lymphocyte associated protein 4-A, $C D 40$ cluster of differentiation 40, HLA human leukocyte antigen, $T G$ thyroglobulin, TSHR thyroid stimulating hormone receptor, $T$ cell $\mathrm{T}$ lymphocytes, $B$ cell B lymphocytes, TSH thyroid stimulating hormone

causes of hyperthyroidism, toxic nodular goiter and Graves' disease are frequently detected in older and younger women, respectively [9].

Graves' disease is mainly characterized by diffuse goiter and hypersecretion of thyroid hormones. Symptoms develop gradually and mainly consist of unintended loss of weight, intolerance to heat, weakness in the muscle, insomnia, tachycardia, increased sweating, irritability, restlessness, nervousness/anxiousness, and fatigue. In addition, patients with this disease may exhibit the symptoms of brittle nails, hair loss, hyperreflexia, increased appetite, and frequent bowel movements, irregular menstrual cycles in females, and erectile dysfunction in males. Graves' disease is sometimes associated with protrusion of the eyeballs from their sockets referred to as Graves' ophthalmopathy. Rarely, Graves' disease develops thickened, reddish skin lesions called pretibial myxedema. Graves' disease might cause congestive heart failure and osteoporosis [10].

Despite Graves' disease is an autoimmune issue, many other components including environmental, genetic, and immunological factors may also significantly contribute to this disease (Table 1). Graves' disease is frequently associated with high titres of thyroid-stimulating immunoglobulins, which activate the TSH receptor in a manner similar to TSH itself (Table 2). It is generally treated with antithyroid drugs (ATDs) like thionamides, radioactive iodine, or thyroidectomy depending on a number of factors including the age of the patient and degree of the illness. Methimazole is the most commonly used ATD to treat this condition, which is approved by the American Thyroid Association (ATA) and the American Association of Clinical Endocrinology (AACE) as first-line therapy notably in young patients ( $<18$ years old), while propylthiouracil is administered at special cases particularly in preterm pregnancies and thyroid storm. Radioactive iodine is most commonly used to treat Graves' disease in the U.S.A. Surgery (thyroidectomy) is used as a definitive therapy to remove a part or entire thyroid gland that may often result in hypothyroidism and needs a life-long supplementation of thyroid hormones. Beta-blocker (propranolol) are prescribed to block the hormone, which is secreted earlier in the bloodstream, and therapy is not withdrawn when thyroid hormone reaches within the normal range. Per available guidelines, for patients on ATDs, once euthyroidism is attained, therapy is continued for 12-18 months with patients and ascertained that the patients remain in an euthyroid state before attempting treatment discontinuation. Corticosteroids, prednisone is used to treat severe Graves' ophthalmopathy cases to decrease tissue inflammation around the eyes [10, 11].

\section{SARS-CoV-2 induces Graves' disease}

Recently, a study published two patients with Graves' disease in connection with the COVID-19 [6]. Additional cases were subsequently reported. As of today, five cases of SARS-CoV-2 infection-induced Graves' disease (autoimmune hyperthyroidism) have been described by three independent groups while two from Spain and one from the U.S.A. [6, 7, 12]. All of these cases of hyperthyroidism were diagnosed in females at least 30-60 days from the day of COVID-19 inception. All of these patients were in the age range of 21-61 years. Of five cases, three displayed earlier issues of thyroid disorder (Graves' disease), and all the episodes were treated with anti-thyroid drugs (ATDs). One case had a previous history of Graves' ophthalmopathy that was reported to be treated with glucocorticoids for 3 months and she was euthyroid till the onset of COVID-19. However, all cases were shown to be treated appropriately and were in remission for many years, and thyroid hormone profile was within the normal range during the previous visits to the clinic. For COVID-19 diagnosis, all the cases 
Table 2 Antibodies involved in Graves' disease (autoimmune hyperthyroidism)

\begin{tabular}{ll}
\hline Antibodies & Level of presence \\
\hline TSAb & Elevated \\
TSBAb & Elevated \\
TBII & Elevated rarely \\
Anti-TPOAb & Elevated (80\%) \\
Anti-TGAb & Elevated (50\%) \\
Antibodies reacting to the iodide symporter & Detectable \\
Antibodies binding to the iodide symporter & Detectable \\
pendrin protein & \\
Antibodies recognizing components of eye & Detectable \\
muscle and/or fibroblasts & \\
Antibodies to DNA & Detectable (low titer) \\
Antibodies reacting to parietal cells & Detectable (infrequent) \\
Antibodies binding to platelets & Detectable \\
\hline
\end{tabular}

$T S A b$ thyroid stimulating antibody, TSBA $b$ TSH-stimulation blocking antibody, TBII thyrotropin-binding inhibitory immunoglobulin,

anti-TPO antibody anti-thyroid peroxidase antibody, anti-TGAb anti-thyroglobulin antibody, DNA deoxyribonucleic acid

were reported to be tested by real-time reverse transcriptionpolymerase chain reaction (RT-PCR) using the nasal swab samples. Although two cases were not positive initially, after 4 days, the examination of lung ultrasound revealed interstitial pneumonia consistent with COVID-19 positivity in one case. Alternatively, $\operatorname{IgM}$ and $\operatorname{IgG}$ antibodies towards SARS-CoV-2 were also tested to be positive in the same patient. The other case has been confirmed as COVID-19 positive later by positive $\mathrm{IgG}$ and bilateral pneumonia.

All the patients commonly developed palpitations. In addition to this symptom, two cases had nervousness, one case showed fatigue and another case developed a tremor. Profiling the thyroid hormones ascertained reduced serum thyroid-stimulating hormone (TSH), increased triiodothyronine (FT3), and thyroxine (FT4). In addition, anti-thyroid stimulating hormone receptor-antibody (anti-TSHR-Ab), thyroperoxidase (TPOAb), and thyroglobulin antibodies ( $\mathrm{TgAb}$ ) were detected to be positive. Iodine uptake was increased with uniform tracer uptake with the range of $30-61 \%$ at $2 \mathrm{~h}$ and $45.7-62 \%$ at $24 \mathrm{~h}$ after administration of ${ }^{131} \mathrm{I}(100 \mu \mathrm{Ci})$. Thyroid ultrasound showed hypervascularity of the thyroid paranchyma. All the assessed patient's clinical profiles, enhanced thyroid uptake, and positive TSHR$\mathrm{Ab}$ were consistently indicated Graves' disease (autoimmune hyperthyroidism). All the patients were treated with a range of 10-40 mg daily dose of methimazole (MMI) for three months. Patients reached euthyroidism three months later and continued to take medication daily dose of $5 \mathrm{mg}$ MMI and ophthalmopathy did not deteriorate. In two cases, propranolol was shown to be combined with MMI that could help to improve both the symptoms and thyroid function (Table 3).

\section{SARS-CoV-2-induced Graves' disease: the pivotal role of autoimmune factors}

Graves' disease often causes hyperthyroidism particularly in females of mid-age. Among the five COVID-19associated Graves' disease cases, three patients displayed a past record of Graves' disease nonetheless, they were in remission for many years and reported maintaining normal thyroid function until they contracted the infection. Alternatively, stress has also been implicated in the relapses of Graves' disease [13]. Furthermore, many viral infections have been considered environmental factors and reported to play a central role in the pathogenesis of autoimmunerelated thyroid disorders [14]. Thus, the concurrently presented five cases show that the SARS-CoV-2 infection could have triggered autoimmune hyperthyroidism, Graves' disease. Many COVID-19-induced autoimmune diseases include autoimmune hemolytic anemia, Guillain-Barré syndrome, and autoimmune thrombocytopenic purpura have been reported for the past year particularly since the SARS-CoV-2 outbreak in December 2019. In addition, many cases of subacute thyroiditis have been recently reported [15-17]. The rapid research outcome on COVID19-related autoimmune diseases suggests that the SARSCoV-2 virus could play a part as a driver of latent or newonset autoimmunity. As commonly observed in other autoimmune disorders, SARS-CoV-2 infection-related hyper-inflammatory condition is likely could have set off an immunological avalanche that activates/reactivates the autoimmune hyperthyroidism, Graves' disease. Consistent with this phenomenon, enhanced levels of IL-6 have been detected in Graves' disease by previous studies [18]. Similarly, SARS-CoV-2-associated hyper-inflammatory cascade has also been found to be regulated particularly by type $1 \mathrm{~T}$ helper cells (Th1) and IL-6 [19]. Conversely, Graves' disease pathogenesis has possibly been shown to be mediated by the autoimmune response of Th2 [20]. It is conceivable that cytokines may exercise multiple and complex signaling effects upon binding with their receptors in the cell. The recent understanding of the pivotal functions of the novel T lymphocytes (Th17 and Th22) and their cytokines in autoimmune thyroid disease (AITD) pathogenesis reveals to revisit the Th1 and Th2 archetype in the pathophysiology of not only the Graves' disease but also the Hashimoto thyroiditis [21].

Initially, the phenotypic expression of thyroid autoimmunity has been thought that it is the balance between the immune responses of Th1 and Th2. A predominant Th1mediated immune response is likely to trigger apoptotic pathways in thyroid follicular cells that could result in the 


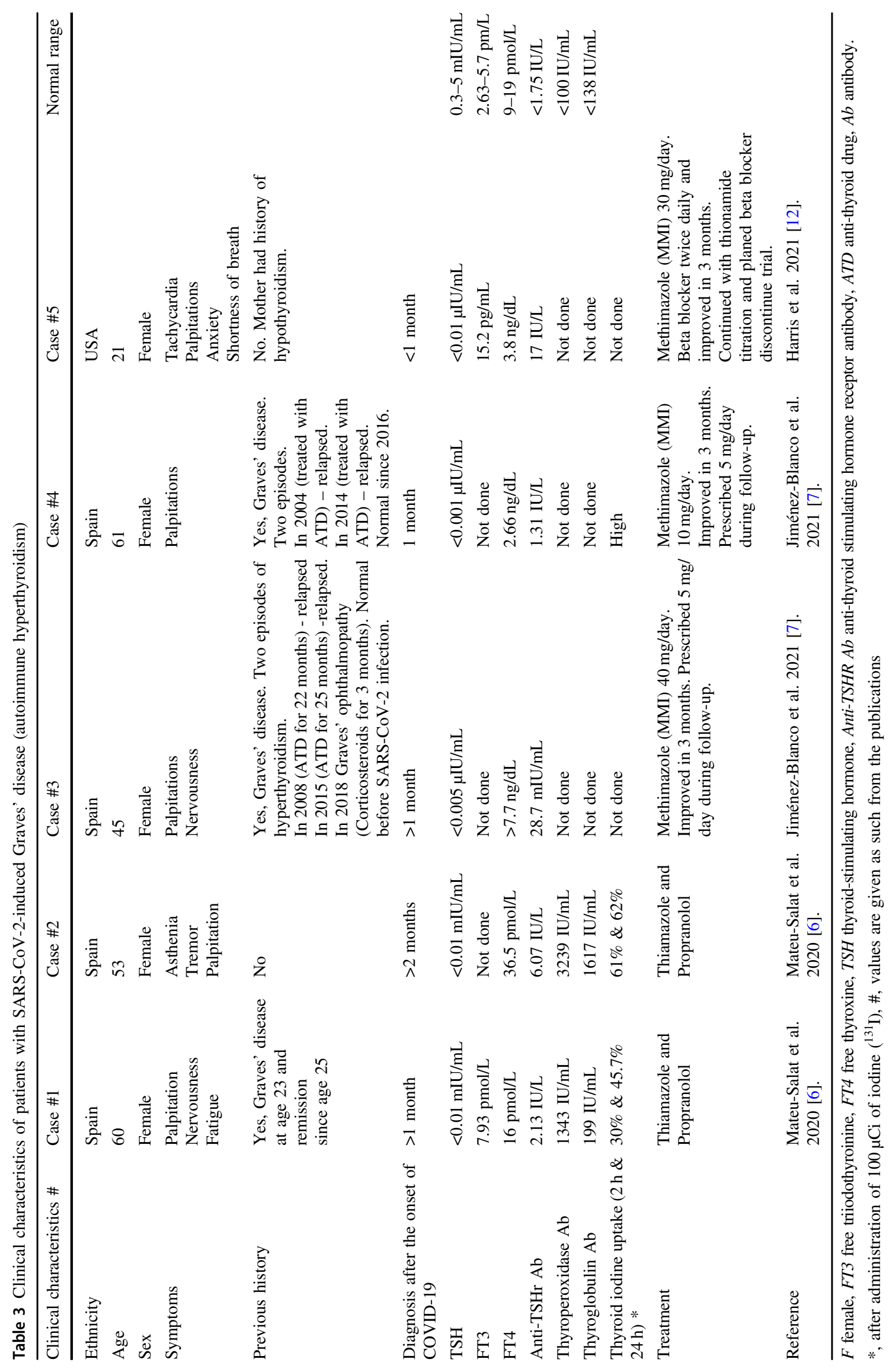


destruction of thyroid cells. On the other hand, Th2mediated immune activity is likely to activate antigenspecific B lymphocytes to make TSHR-Abs that results in thyroid cell proliferation and hyperactivity of the thyroid gland. For example, in some cases, stress has been reported to shift the Th1 and Th2 balance towards Th2 that favors the development of Graves' disease, while the relief of stress/ immune-suppressive effect reverses the effect towards Th1 resulting in postpartum autoimmune thyroiditis [22]. T cells have been shown to maintain the chronic inflammation in Graves' disease as the Th1 and Th2 cells were detected in the intrathyroidal infiltrate and reacted readily to both TSHR peptides and TSHR antigen [23-33]. T cell receptor (TCR) genes have been detected in the $\mathrm{T}$ cells, which infiltrate the thyroid gland in Graves' disease [28, 29], reflecting the clonal expansion and it suggests a fundamental nature of $\mathrm{T}$ cell response in this process. Some differences have also been found in the use of specific TCR in some patients because T cells could identify the TSHR, only when the major histocompatibility complex (MHC) molecules are in the right context [30, 34].

Moreover, regulatory $\mathrm{CD}^{+} \mathrm{T}$ cells (Tregs) inhibit effector T cells, and any deficiency in Tregs results in the development of autoimmunity [35]. Expression of $\alpha$ chain of the IL-2 receptor (CD25), mostly on the surface of cells $\left(\mathrm{CD} 4^{+} \mathrm{T}\right)$ and forkhead family transcription factor (FoxP3) are critically important for the evolution and perpetuation of Treg function. It has been found that the naïve $\mathrm{CD} 4^{+} \mathrm{T}$ cells could differentiate into Th1, Th2, Th17, and Tregs, and it is exclusively dependent on the context of cytokine milieu. Studies on cell lines and animal models established that $\mathrm{CD}^{+} \mathrm{T}$ cells exhibit polarization of some cytokines mainly toward Th17 cells which produce cytokine, IL-17. These studies also revealed that IL-12, IL-4, transforming growth factor- $\beta$ (TGF- $\beta$ ), and IL- $6+$ TGF- $\beta$ skew toward Th 1 , Th2, Tregs, and Th17 cells, respectively [36-39]. Besides, rather than the differentiation of Treg, Th17, or Th1 activity was expected to be accountable for the evolution and progression of the autoimmune disease [39].

Development of Graves' disease has been documented in a patient who had transplanted $\mathrm{CD} 34^{+}$selected autologous stem cells and another two cases of Graves' disease out of 25 cases who were transplanted with autologous hematopoietic stem cells suggesting the importance of the Th17 cells in Graves' disease [40, 41]. Notably, enhanced levels of IL- 6 and TGF- $\beta$ cytokines were shown to be detected prior to the elevated Th17 levels in those cases reflected that priming of these cells (autologous stem-cells) by IL-6, and TGF- $\beta$ was needed to trigger the pathogenic Th17 cells and consecutive evolution of autoreactive TSHR-specific B cells (Fig. 2). Consistently, a current study evidenced that SARS$\mathrm{CoV}-2$ infection-associated hyper inflammation could induce Th17 [19]. These results suggest that the viral- induced Graves' disease (autoimmune hyperthyroidism) is likely to be mediated by Th17. Nevertheless, further studies are warranted to affirm this conclusion.

\section{Hyperthyroidism patients: are they highly vulnerable to SARS-CoV-2 infection?}

The cardiac renin-angiotensin-aldosterone system (RAAS) has been reported to be activated in hyperthyroidism and that could escalate cardiac renin function and angiotensin II (Ang II) levels [42]. Besides, the cardiac angiotensin II receptor type 2 (AT2 receptor) was shown to be upregulated in response to hyperthyroidism, suggesting that there are alterations of key molecules of the major axis of RAAS in hyperthyroidism. Use of angiotensin-converting enzyme (ACE) or angiotensin II receptor type 1 (AT1 receptor) inhibitory drugs were shown to depreciate RAAS in cardiac cell proliferation due to enhanced thyroid hormone and suggest that RAAS acts a pivotal part in thyroid hormonemediated cardiac hypertrophy [42].

Furthermore, it has been demonstrated that hypertrophyinduced autoregulatory factor could hyperactivate ACE. Angiotensin 1-7 levels in plasma were unaltered by hyperthyroidism, yet, the amount of cardiac Ang 1-7 was elevated in cardiac hypertrophy triggered by thyroid hormones. Also, significantly enhanced enzymatic activity of ACE2 was detected in the hearts of hyperthyroid animals that could be the reason for elevated Ang 1-7. Consistently, the enhanced cardiac Ang 1-7 levels were shown to be conjugated by elevated Mas receptor proteins. These results reflect that counter-regulatory components of the RAAS are accelerated in hyperthyroidism that could contribute to regulate cardiac hypertrophy in response to thyroid hormone [43].

The role of ACE2 in the association between cardiac hypertrophy and COVID-19 is plausible. ACE2 consists of a peptidase (PD) and collectrin-like domain (CLD) ending with a transmembrane-helix that has a cellular portion $(\sim 40$ residues) in the $\mathrm{N}$ - and $\mathrm{C}$-terminal, respectively. The ACE2 is highly localized in the epithelial cells of the lungs, heart, kidneys, blood vessels, small intestine, testes, adipose tissue and thyroid gland, and it controls vasoconstriction and blood pressure [4]. Peptidase domain of ACE2 enzyme catalyzes the Ang II into a smaller molecule, Ang 1-7 and to some extent Ang I into Ang 1-9 that is subsequently primed by some different enzymes into Ang 1-7. In addition, ACE2/Ang 1-7 plays a key role in anti-inflammation and anti-oxidant conditions to protect the lungs against acute respiratory distress syndrome (ARDS) [44]. The ACE2 expression is increased in patients with hyperthyroidism possibly due to cardiac hypertrophy and hence this might explain the enhanced predisposition to critical lung injuries and ARDS in people suffering from COVID-19 and hyperthyroidism. 


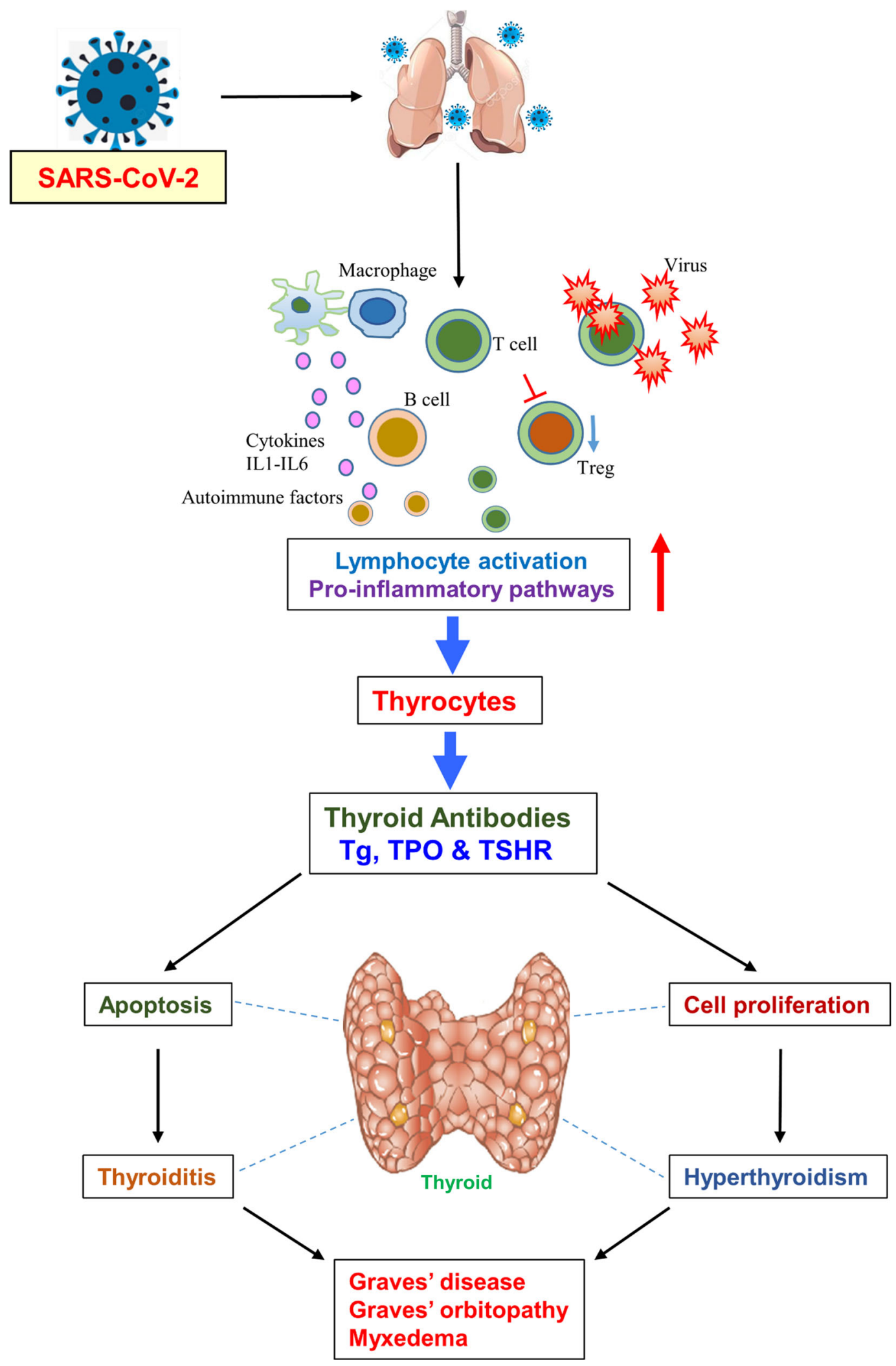

Overexpression of ACE2 has detrimental effects on patients with COVID-19. SARS-CoV-2 exploits the ACE2 to enter into pneumocytes of the host as SARS-CoV-2 "spike protein" (S) on the virion external portion directly binds to PD of the
ACE2 [1]. Importantly, when the hyperthyroid patients with hypertrophy/hypertension are treated with the ACE inhibitors (ACEi) or Ang II receptor blockers (ARBs) and use of ACE2stimulating drugs, the ACE2 expression is significantly 
4 Fig. 2 SARS-CoV-2 infection-mediated Graves' disease (autoimmune hyperthyroidism). The illustration shows the outline of various factors and steps possibly involved in the SARS-CoV-2 infection-mediated development of autoimmune hyperthyroidism, Graves' disease. Specific lymphocyte production and pro-inflammatory pathway activation, and Treg downregulation may promote thyrocytes for the generation of thyroid antibodies that induce apoptosis, which leads to thyroiditis on one side, and on the other side, the antibodies trigger cell proliferation that results in hyperthyroidism

elevated in those patients to counterbalance the increased levels of Ang-I and Ang-II because of an adaptive response. Furthermore, various drugs including pioglitazone, ibuprofen, and liraglutide were also reported to upregulate ACE2 in animals [45]. Therefore, elevated ACE2 would facilitate the entry of SARS-CoV-2 into pneumocytes. Consistent with this idea, a recent study concluded that severely ill patients infected with COVID-19 displayed a higher incidence of hypokalemia resulting from the waste of renal potassium. This might be due to downregulation of ACE2 followed by SARS-CoV-2 entry may result in diminished degradation of Ang II, increased AT2 receptor expression, enhanced aldosterone secretion, and consequently elevated loss of urinary potassium. It has been proposed that early normalization of serum potassium in COVID-19 patients may predict a better prognosis [46]. Therefore, enhanced expression of ACE2 aberrantly drives two physiological processes, on the one hand, it helps intrusion of SARS-CoV-2 in the cells, on the other hand, it is helpless to safeguard against injury of lungs since the ACE2 enzyme gets degraded by the SARS-CoV-2 which collectively enhances the risk of complications and destabilizes the patient to a fatal condition (Fig. 3). Many mechanistic insights have been shown that hyperthyroidism could induce cardiac hypertrophy and an increased ACE2 expression [4, 42, 43]. Moreover, the expression of ACE2 was demonstrated to be the critical component for the SARS-CoV-2 infection [1]. These studies together postulate that people with hyperthyroidism are apparently at greater risk for SARS-CoV-2 infection and related COVID-19 complications. In accordance with this view, a recent study reported the first case of SARS-CoV-2related thyrotoxic crisis in a patient with a previous history of Graves' disease [47]. In most cases, thyroid storms might emerge owing to prolonged hyperthyroidism with no treatment essentially they get triggered off because of an acute inherent issue [48] or treatment denial is one of the primary drivers in earlier-detected hyperthyroidism cases in the course of an infection [49]. As in this studied case, SARS-CoV-2 may also induce a thyrotoxic crisis in people with a previous history of Graves' disease suggesting that the prominence of SARSCoV2 in precipitating thyroid storm.

\section{Antithyroid medications and COVID-19}

Hyperthyroidism and Graves' disease patients are commonly treated with methimazole or propylthiouracil (PTU).
Though the antithyroid drugs are effective in treating Graves' disease, they may cause side effects even at low doses of the medication. Mainly, some of these side effects are potentially serious. For example, agranulocytosis is a serious side effect that is noticed among $0.2-0.5 \%$ of people taking any one of these drugs [49].

Likewise, patients who receive antithyroid medications may also have fever or sore throat [50]. As these signs of illness could also overlap with the symptoms of COVID-19, many patients who take these drugs may be concerned that they are infected with SARS-CoV-2 and become panic. Alternatively, patients may confuse symptoms of COVID19 with side effects of ATDs. Therefore, people with hyperthyroidism should ensure that they have better control of hyperthyroidism with adequate medication which can improve good heart health and this may boost hostmediated immune response. Thus, it is desirable that all people having underlying comorbidities including hyperthyroidism should take extra precautions not to contract the virus as thus far therapeutic medications are not found.

\section{Thyroid disease is associated with the severity of COVID-19}

A recent study performed a meta-analysis with a total of 2169 cases with COVID-19 disease which included the patients from eight different reports [50-57]. Results obtained from the meta-analyses showed that preexisting thyroid disease is likely connected with an enhanced vulnerability of SARS-CoV-2 infection and suggested that thyroid disease presence can be considered as an important factor for COVID-19 disease risk stratification models [58].

It is noteworthy that the thyroid hormones are essential for the innate immune response regulation and any changes in the levels of thyroid hormone proportionately deregulate the innate immunity [59]. Innate immune responses have been demonstrated as front-line factors of the body to combat the SARS-CoV-2 infection and associated COVID-19, which is frequently reflected by significantly elevated levels of $\mathrm{CD} 14^{+}$ monocytes, macrophages, neutrophils, and reduced levels of natural killer (NK) cells in SARS-CoV-2-affected cases [60]. Besides, it has been observed that the pro-inflammatory cytokines including TNF- $\alpha$ and IL- 6 were considerably enhanced in cases having thyroid disease [61]. Consistent with the notion, enhanced levels of cytokines have been found in severe COVID-19 patients and associated with the progression to poor outcomes [62]. On the other hand, corticosteroids' utility as an immunosuppressive therapeutics in COVID-19 cases has clearly been shown to be associated with a high rate of bacterial infection, a longer stay in the hospital, and higher mortality [63]. Beyond the bounds, the innate immune system is also likely accountable for mediating the presumptive organ damage of autoimmune diseases. Mainly, this cascade 


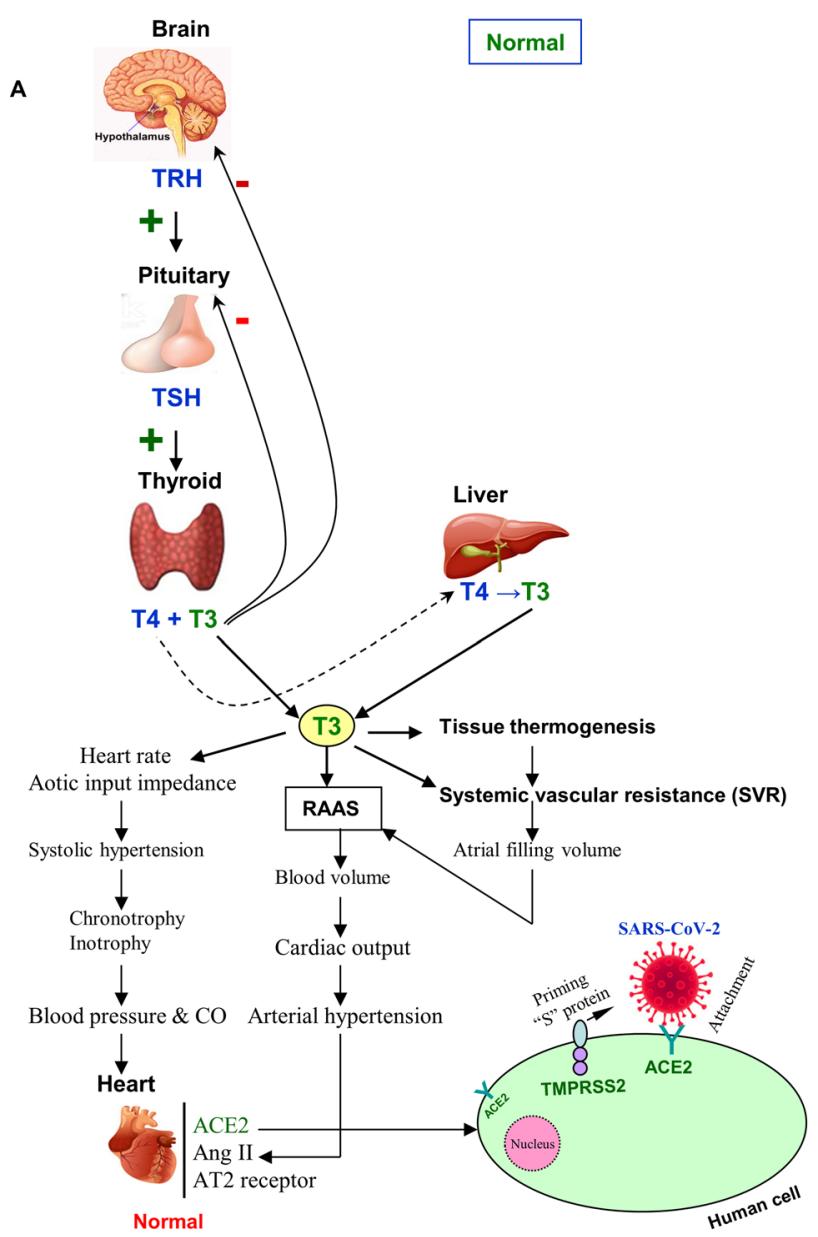

Fig. 3 Hyperthyroidism-induced cardiac hypertrophy and its role in COVID-19 disease risk. a The illustration shows a normal thyroid function. Thyroid hormone-mediated regulation of various cellular physiological pathways including RAAS and its less susceptibility to SARS-CoV-2 infection. b The schematic diagram shows hyperthyroidism-induced hypertrophy and its enhanced risk in contracting SARS-CoV-2. Hyperthyroidism upregulates various downstream signaling including the RAAS that results in cardiac

generates pro-inflammatory cytokines that magnify the local inflammation signal in addition to triggering proximal parenchymal or other immune cells. Furthermore, the generation of matrix-degrading and proteolytic enzymes or reactive oxygen species (ROS) leads to tissue damage, albeit microbial cues are one of the prerequisites to develop autoimmune disease [64].

\section{Other factors recently implicated in inducing Graves' disease}

Immune-related unwanted secondary effects are called immune-related adverse events (irAEs) and thyroid disorders are often caused by irAE [65]. On the other hand, adjuvants particularly vaccines were reported to ignite various undesirable immune response that causes a

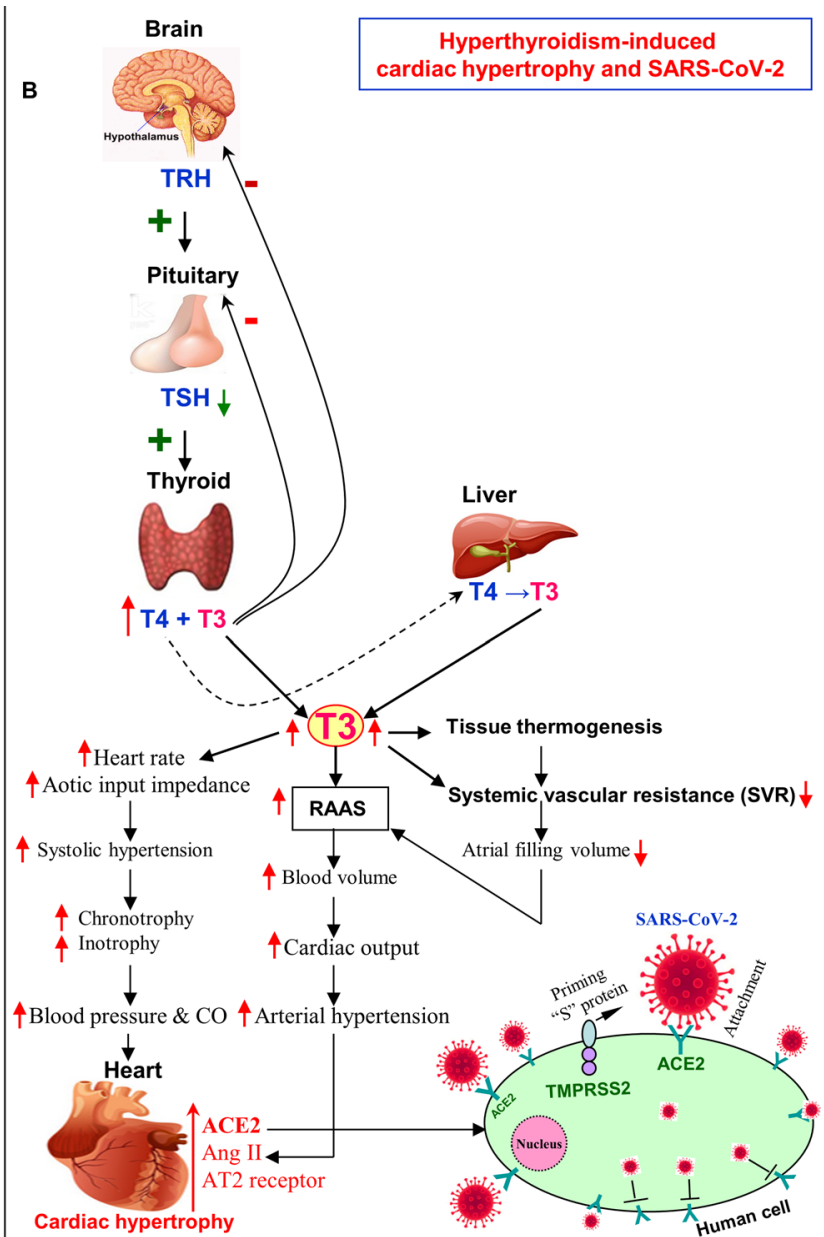

hypertrophy which enhances expression of ACE2, Ang II, and Mas receptor by counter-regulatory components of the RAAS. Highly expressed ACE2 accelerates cellular access to SARS-CoV-2. This is followed by rapid replication of the virus and downregulation of ACE2 expression this results in reduced degradation of Ang II leading to elevated aldosterone secretion and waste of renal potassium which markedly increases the rates of cardiac and renal-associated morbidity and mortality of COVID-19 patients

spectrum of autoimmune disorders (AIDs) which also include thyroid diseases [66]. Recently, two SARS-CoV-2 vaccine-induced Graves' disease cases were reported [67]. This incidence was observed in two health care workers after 2-3 days of Pfizer-BioNTech (BNT162B2 SARS$\mathrm{CoV}-2)$ vaccination. These patients well-responded to the conventional therapies (propranolol 40-60 mg, thiamazole $10 \mathrm{mg}$ with/without diltiazem $120 \mathrm{mg}$, and ivabradine $5 \mathrm{mg}$ daily) and recovered [67]. This autoimmune/inflammatory condition induced by adjuvants termed autoimmune syndromes-induced by adjuvants (ASIA). Most of the constituents of the vaccines are safe but a few substances including polyethylene glycol (PEG) are likely to act as an adjuvant by inducing an immune response, despite scarce [68]. Yet, the currently noticed, Graves' disease in vaccinated cases certainly indicates that it is a pathological 
phenomenon of autoimmune conditions induced by adjuvants. In fact, similar clinical conditions have already been observed in cancer patients who were treated with immunecheckpoint inhibitors (ICPis). Particularly, the ICPis including anti-CTLA-4 (ipilimumab and tremelimumab) and anti-programmed cell death protein-1 (anti-PD-1) (pembrolizumab and nivolumab) were shown to induce Graves' hyperthyroidism/Graves' ophthalmopathy in immune-checkpoint inhibitor-treated cancer patients. They were reported to be medically managed either with glucocorticoids or methimazole/carbimazole while rarely performed thyroidectomy [69]. These findings suggest that factors inducing autoimmune and/or inflammatory conditions may also have a risk to trigger Graves' disease regardless of their diversity.

\section{Conclusions and future prospective}

Recent studies reveal that the SARS-CoV-2 infection could cause Graves' disease, an autoimmune hyperthyroidism in the post-COVID-19 cases. Various autoimmune factors may mediate complex pathogenic signaling in autoimmune hyperthyroidism. Future studies are warranted to rule out the autoimmune factors and molecular pathways implicated in SARS-CoV-2-induced autoimmune hyperthyroidism. Further, related findings suggest that people with hyperthyroidism are likely at an enhanced risk of severe and deadly COVID-19 disease regardless of the underlying other etiological factors. Various comorbid conditions including thyroid disease have been reported to enhance the risk of a part of larger human communities in the world to SARS-CoV-2 and its related COVID-19 complications that may collectively result in high mortality. The direct functional relationship of thyroid gland with COVID-19 is rapidly evolving and this scenario alerts researchers and/or physicians in this field for careful observation of other and unrecorded clinical phenomena in relation to COVID-19.

\section{Data availability}

All the data related to this manuscript is available within the article.

\section{Compliance with ethical standards}

Conflict of interest The authors declare no competing interests.

Ethical approval All procedures performed in studies involving human participants were in accordance with the ethical standards of the institutional and/or national research committee and with the 1964 Helsinki declaration and its later amendments or comparable ethical standards. This review article does not contain/report any primary data from humans or animals.
Publisher's note Springer Nature remains neutral with regard to jurisdictional claims in published maps and institutional affiliations.

\section{References}

1. M. Hoffmann, H. Kleine-Weber, S. Schroeder, N. Krüger, T. Herrler, S. Erichsen, T.S. Schiergens, G. Herrler, N.H. Wu, A. Nitsche, M.A. Müller, C. Drosten, S. Pöhlmann, SARS-CoV-2 cell entry depends on ACE2 and TMPRSS2 and is blocked by a clinically proven protease inhibitor. Cell 181(2), 271-280.e8 (2020). https://doi.org/10.1016/j.cell.2020.02.052

2. COVID-19 data portal home page. https://coronavirus.jhu.edu. Accessed on May 11, 2021.

3. W.J. Guan, W.H. Liang, Y. Zhao, H.R. Liang, Z.S. Chen, Y.M. Li, X.Q. Liu, R.C. Chen, C.L. Tang, T. Wang, C.Q. Ou, L. Li, P. Y. Chen, L. Sang, W. Wang, J.F. Li, C.C. Li, L.M. Ou, B. Cheng, S. Xiong, Z.Y. Ni, J. Xiang, Y. Hu, L. Liu, H. Shan, C.L. Lei, Y. X. Peng, L. Wei, Y. Liu, Y.H. Hu, P. Peng, J.M. Wang, J.Y. Liu, Z. Chen, G. Li, Z.J. Zheng, S.Q. Qiu, J. Luo, C.J. Ye, S.Y. Zhu, L. L. Cheng, F. Ye, S.Y. Li, J.P. Zheng, N.F. Zhang, N.S. Zhong, J. $\mathrm{X}$. He, Comorbidity and its impact on 1590 patients with COVID19 in China: a nationwide analysis. Eur. Respir. J. 55(5), 2000547 (2020). https://doi.org/10.1183/13993003.00547-2020

4. M.Y. Li, L. Li, Y. Zhang, X.S. Wang, Expression of the SARSCoV-2 cell receptor gene ACE2 in a wide variety of human tissues. Infect. Dis. Poverty 9(1), 45 (2020). https://doi.org/10.1186/ s40249-020-00662-x

5. A. Lania, M.T. Sandri, M. Cellini, M. Mirani, E. Lavezzi, G. Mazziotti, Thyrotoxicosis in patients with COVID-19: the THYRCOV study. Eur. J. Endocrinol. 183(4), 381-387 (2020). https://doi.org/10.1530/EJE-20-0335

6. M. Mateu-Salat, E. Urgell, A. Chico, SARS-COV-2 as a trigger for autoimmune disease: report of two cases of Graves' disease after COVID-19. J. Endocrinol. Invest. 43(10), 1527-1528 (2020). https://doi.org/10.1007/s40618-020-01366-7

7. S. Jiménez-Blanco, B. Pla-Peris, M. Marazuela, COVID-19: a cause of recurrent Graves' hyperthyroidism? J. Endocrinol. Invest. 44(2), 387-388 (2021). https://doi.org/10.1007/s40618-02001440-0

8. R. Mullur, Y.Y. Liu, G.A. Brent, Thyroid hormone regulation of metabolism. Physiol. Rev. 94(2), 355-382 (2014). https://doi.org/ 10.1152/physrev.00030.2013

9. P.N. Taylor, D. Albrecht, A. Scholz, G. Gutierrez-Buey, J.H. Lazarus, C.M. Dayan, O.E. Okosieme, Global epidemiology of hyperthyroidism and hypothyroidism. Nat. Rev. Endocrinol. 14 (5), 301-316 (2018). https://doi.org/10.1038/nrendo.2018.18

10. A. Antonelli, S.M. Ferrari, F. Ragusa, G. Elia, S.R. Paparo, I. Ruffilli, A. Patrizio, C. Giusti, D. Gonnella, A. Cristaudo, R. Foddis, Y. Shoenfeld, P. Fallahi, Graves' disease: epidemiology, genetic and environmental risk factors and viruses. Best. Pract. Res. Clin. Endocrinol. Metab. 34(1), 101387 (2020). https://doi. org/10.1016/j.beem.2020.101387

11. T.J. Smith, L. Hegedüs, Graves' disease. N. Engl. J. Med. 375 (16), 1552-1565 (2016). https://doi.org/10.1056/NEJMra1510030

12. A. Harris, M.A.L. Mushref, Graves' thyrotoxicosis following SARS-CoV-2 infection. AACE Clin. Case Rep. 7(1), 14-16 (2021). https://doi.org/10.1016/j.aace.2020.12.005

13. R. Vita, D. Lapa, F. Trimarchi, S. Benvenga, Stress triggers the onset and the recurrences of hyperthyroidism in patients with Graves' disease. Endocrine 48(1), 254-263 (2015). https://doi.org/ 10.1007/s12020-014-0289-8

14. M.F. Prummel, T. Strieder, W.M. Wiersinga, The environment and autoimmune thyroid diseases. Eur. J. Endocrinol. 150(5), 605-618 (2004). https://doi.org/10.1530/eje.0.1500605 
15. E. Asfuroglu Kalkan, I. Ates, A case of subacute thyroiditis associated with Covid-19 infection. J. Endocrinol. Invest. 43(8), 1173-1174 (2020). https://doi.org/10.1007/s40618-020-01316-3

16. S. Ippolito, F. Dentali, M.L. Tanda, SARS-CoV-2: a potential trigger for subacute thyroiditis? Insights from a case report. J. Endocrinol. Invest. 43(8), 1171-1172 (2020). https://doi.org/10. 1007/s40618-020-01312-7

17. A. Brancatella, D. Ricci, N. Viola, D. Sgrò, F. Santini, F. Latrofa, Subacute thyroiditis after Sars-COV-2 infection. J. Clin. Endocrinol. Metab. 105(7), dgaa276 (2020). https://doi.org/10.1210/ clinem/dgaa276

18. M. Salvi, G. Girasole, M. Pedrazzoni, M. Passeri, N. Giuliani, R. Minelli, L.E. Braverman, E. Roti, Increased serum concentrations of interleukin-6 (IL-6) and soluble IL-6 receptor in patients with Graves' disease. J. Clin. Endocrinol. Metab. 81(8), 2976-2979 (1996). https://doi.org/10.1210/jcem.81.8.8768861

19. V.J. Costela-Ruiz, R. Illescas-Montes, J.M. Puerta-Puerta, C. Ruiz, L. Melguizo-Rodríguez, SARS-CoV-2 infection: the role of cytokines in COVID-19 disease. Cytokine Growth Factor Rev. 54, 62-75 (2020). https://doi.org/10.1016/j.cytogfr.2020.06.001

20. S.A. Morshed, R. Latif, T.F. Davies, Delineating the autoimmune mechanisms in Graves' disease. Immunol. Res. 54(1-3), 191-203 (2012). https://doi.org/10.1007/s12026-012-8312-8

21. Q. Li, B. Wang, K. Mu, J.A. Zhang, The pathogenesis of thyroid autoimmune diseases: New T lymphocytes - Cytokines circuits beyond the Th1-Th2 paradigm. J. Cell. Physiol. 234(3), 2204-2216 (2019). https://doi.org/10.1002/jcp.27180

22. A. Tsatsoulis, The role of stress in the clinical expression of thyroid autoimmunity. Ann. N. Y. Acad. Sci. 1088, 382-395 (2006). https://doi.org/10.1196/annals.1366.015

23. J.A. Gilbert, S.L. Kalled, J. Moorhead, D.M. Hess, P. Rennert, Z. Li, M.Z. Khan, J.P. Banga, Treatment of autoimmune hyperthyroidism in a murine model of Graves' disease with tumor necrosis factor-family ligand inhibitors suggests a key role for B cell activating factor in disease pathology. Endocrinology 147 (10), 4561-4568 (2006). https://doi.org/10.1210/en.2006-0507

24. Q. Lai Kwan Lam, O. King Hung, Ko,B.J. Zheng, L. Lu, Local BAFF gene silencing suppresses Th17-cell generation and ameliorates autoimmune arthritis. Proc. Natl Acad. Sci. U. S. A 105(39), 14993-14998 (2008). https://doi.org/10.1073/pnas. 0806044105

25. M. Salvi, G. Vannucchi, I. Campi, S. Rossi, P. Bonara, F. Sbrozzi, C. Guastella, S. Avignone, G. Pirola, R. Ratiglia, P. Beck-Peccoz, Efficacy of rituximab treatment for thyroid-associated ophthalmopathy as a result of intraorbital B-cell depletion in one patient unresponsive to steroid immunosuppression. Eur. J. Endocrinol. 154(4), 511-517 (2006). https://doi.org/10.1530/eje.1.02119

26. C.R. Chen, S.M. McLachlan, B. Rapoport, Suppression of thyrotropin receptor constitutive activity by a monoclonal antibody with inverse agonist activity. Endocrinology 148(5), 2375-2382 (2007). https://doi.org/10.1210/en.2006-1754

27. G. Stassi, R. De, Maria, Autoimmune thyroid disease: new models of cell death in autoimmunity. Nat. Rev. Immunol. 2(3), 195-204 (2002). https://doi.org/10.1038/nri750

28. T.F. Davies, A. Martin, E.S. Concepcion, P. Graves, L. Cohen, A. Ben-Nun, Evidence of limited variability of antigen receptors on intrathyroidal $\mathrm{T}$ cells in autoimmune thyroid disease. N. Engl. J. Med. 325(4), 238-244 (1991). https://doi.org/10.1056/ NEJM199107253250404

29. T.F. Davies, A. Martin, E.S. Concepcion, P. Graves, N. Lahat, W. L. Cohen, A. Ben-Nun, Evidence for selective accumulation of intrathyroidal $\mathrm{T}$ lymphocytes in human autoimmune thyroid disease based on T cell receptor V gene usage. J. Clin. Invest. 89(1), 157-162 (1992). https://doi.org/10.1172/JCI115556

30. C.M. Dayan, M. Londei, A.E. Corcoran, B. Grubeck-Loebenstein, R.F. James, B. Rapoport, M. Feldmann, Autoantigen recognition by thyroid-infiltrating T cells in Graves disease. Proc. Natl Acad. Sci. U. S. A. 88(16), 7415-7419 (1991). https://doi.org/10.1073/ pnas.88.16.7415

31. R.A. Jackson, B.F. Haynes, W.M. Burch, K. Shimizu, M.A. Bowring, G.S. Eisenbarth, Ia $+\mathrm{T}$ cells in new onset Graves' disease. J. Clin. Endocrinol. Metab. 59(2), 187-190 (1984). https://doi.org/10.1210/jcem-59-2-187

32. J.R. Wall, R. Baur, H. Schleusener, P. Bandy-Dafoe, Peripheral blood and intrathyroidal mononuclear cell populations in patients with autoimmune thyroid disorders enumerated using monoclonal antibodies. J. Clin. Endocrinol. Metab. 56(1), 164-169 (1983). https://doi.org/10.1210/jcem-56-1-164

33. A. Martin, G. Barbesino, T.F. Davies, T-cell receptors and autoimmune thyroid disease-signposts for T-cell-antigen driven diseases. Int. Rev. Immunol. 18(1-2), 111-140 (1999). https://doi. org/10.3109/08830189909043021

34. A. Martin, M. Nakashima, A. Zhou, D. Aronson, A.J. Werner, T. F. Davies, Detection of major T cell epitopes on human thyroid stimulating hormone receptor by overriding immune heterogeneity in patients with Graves' disease. J. Clin. Endocrinol. Metab. 82(10), 3361-3366 (1997). https://doi.org/10.1210/jcem. 82.10 .4299

35. S. Sakaguchi, Naturally arising Foxp3-expressing CD25+CD4+ regulatory $\mathrm{T}$ cells in immunological tolerance to self and non-self. Nat. Immunol. 6(4), 345-352 (2005). https://doi.org/10.1038/ ni1178

36. E. Bettelli, Y. Carrier, W. Gao, T. Korn, T.B. Strom, M. Oukka, H.L. Weiner, V.K. Kuchroo, Reciprocal developmental pathways for the generation of pathogenic effector TH17 and regulatory T cells. Nature 441(7090), 235-238 (2006). https://doi.org/10. 1038/nature04753

37. F. Fossiez, O. Djossou, P. Chomarat, L. Flores-Romo, S. AitYahia, C. Maat, J.J. Pin, P. Garrone, E. Garcia, S. Saeland, D. Blanchard, C. Gaillard, B. Das Mahapatra, E. Rouvier, P. Golstein, J. Banchereau, S. Lebecque, T cell interleukin-17 induces stromal cells to produce proinflammatory and hematopoietic cytokines. J. Exp. Med. 183(6), 2593-5603 (1996). https://doi. org/10.1084/jem.183.6.2593

38. E. Lubberts, L.A. Joosten, F.A. van de Loo, P. Schwarzenberger, J. Kolls, W.B. van den Berg, Overexpression of IL-17 in the knee joint of collagen type II immunized mice promotes collagen arthritis and aggravates joint destruction. Inflamm. Res. 51(2), 102-104 (2002). https://doi.org/10.1007/BF02684010

39. B. Afzali, G. Lombardi, R.I. Lechler, G.M. Lord, The role of T helper 17 (Th17) and regulatory T cells (Treg) in human organ transplantation and autoimmune disease. Clin. Exp. Immunol. 148 (1), 32-46 (2007). https://doi.org/10.1111/j.1365-2249.2007. 03356.x

40. T. Bohgaki, T. Atsumi, T. Koike, Autoimmune disease after autologous hematopoietic stem cell transplantation. Autoimmun. Rev. 7(3), 198-203 (2008). https://doi.org/10.1016/j.autrev.2007. 11.005

41. T. Bohgaki, T. Atsumi, T. Koike, Multiple autoimmune diseases after autologous stem-cell transplantation. N. Engl. J. Med. 357 (26), 2734-2736 (2007). https://doi.org/10.1056/NEJMc076383

42. M.L. Barreto-Chaves, N. Senger, M. Fevereiro, A.C. Parletta, A. Takano, Impact of hyperthyroidism on cardiac hypertrophy. Endocr. Connect 9(3), R59-R69 (2020). https://doi.org/10.1530/ EC-19-0543

43. G.P. Diniz, N. Senger, M.S. Carneiro-Ramos, R.A. Santos, M.L. Barreto-Chaves, Cardiac ACE2/angiotensin 1-7/Mas receptor axis is activated in thyroid hormone-induced cardiac hypertrophy. Ther. Adv. Cardiovasc. Dis. 10(4), 192-202 (2016). https://doi. org/10.1177/1753944715623228

44. R. Yan, Y. Zhang, Y. Li, L. Xia, Y. Guo, Q. Zhou, Structural basis for the recognition of SARS-CoV-2 by full-length human 
ACE2. Science 367(6485), 1444-1448 (2020). https://doi.org/10. 1126/science.abb2762

45. C. Bavishi, T.M. Maddox, F.H. Messerli, Coronavirus disease 2019 (COVID-19) infection and renin angiotensin system blockers. JAMA Cardiol. 5(7), 745-747 (2020). https://doi.org/10. 1001/jamacardio.2020.1282

46. G. Lippi, A.M. South, B.M. Henry, Electrolyte imbalances in patients with severe coronavirus disease 2019 (COVID-19). Ann. Clin. Biochem. 57(3), 262-265 (2020). https://doi.org/10.1177/ 0004563220922255

47. S. Pastor, Á. Sr. Molina, E. De Celis, Thyrotoxic Crisis and COVID-19 Infection: An Extraordinary Case and Literature Review. Cureus 12(11), e11305 (2020). https://doi.org/10.7759/ cureus. 11305

48. S. Swee du, C.L. Chng, A. Lim, Clinical characteristics and outcome of thyroid storm: a case series and review of neuropsychiatric derangements in thyrotoxicosis. Endocr. Pract. 21 (2), 182-189 (2015). https://doi.org/10.4158/EP14023.OR

49. K. Boelaert, W.E. Visser, P.N. Taylor, C. Moran, J. Léger, L. Persani, ENDOCRINOLOGY IN THE TIME OF COVID-19: management of hyperthyroidism and hypothyroidism. Eur. J. Endocrinol. 183(1), G33-G39 (2020). https://doi.org/10.1530/ EJE-20-0445

50. S. Almazeedi, S. Al-Youha, M.H. Jamal, M. Al-Haddad, A. AlMuhaini, F. Al-Ghimlas, S. Al-Sabah, Characteristics, risk factors and outcomes among the first consecutive 1096 patients diagnosed with COVID-19 in Kuwait. EClinicalMedicine 24, 100448 (2020). https://doi.org/10.1016/j.eclinm.2020.100448

51. M. Cao, D. Zhang, Y. Wang, Y. Lu, X. Zhu, Y. Li, H. Xue, Y. Lin, M. Zhang, Y. Sun, Z. Yang, J. Shi, Y. Wang, C. Zhou, Y. Dong, P. Liu, S. M. Dudek, Z. Xiao, H. Lu, L. Peng, Clinical features of patients infected with the 2019 novel coronavirus (COVID-19) in Shanghai, China. medRxiv. 2020;2020.03.04.20030395. https://doi. org/10.1101/2020.03.04.20030395.

52. J. Liu, X. Wu, F. Lu, L. Zhao, L. Shi, F. Xu, Low T3 syndrome is a strong predictor of poor outcomes in patients with communityacquired pneumonia. Sci. Rep. 6, 22271 (2016). https://doi.org/10. 1038/srep22271

53. M. Shabrawishi, M.M. Al-Gethamy, A.Y. Naser, M.A. Ghazawi, G.F. Alsharif, E.F. Obaid, H.A. Melebari, D.M. Alamri, A.S. Brinji, F.H. Al Jehani, W. Almaimani, R.A. Ekram, K.H. Alkhatib, H. Alwafi, Clinical, radiological and therapeutic characteristics of patients with COVID-19 in Saudi Arabia. PLoS One 15(8), e0237130 (2020). https://doi.org/10.1371/journal.pone. 0237130

54. A. Sisó-Almirall, B. Kostov, M. Mas-Heredia, S. Vilanova-Rotllan, E. Sequeira-Aymar, M. Sans-Corrales, E. Sant-Arderiu, L. Cayuelas-Redondo, A. Martínez-Pérez, N. García-Plana, A. Anguita-Guimet, J. Benavent-Àreu, Prognostic factors in Spanish COVID-19 patients: a case series from Barcelona. PLoS One 15 (8), e0237960 (2020). https://doi.org/10.1371/journal.pone. 0237960

55. Y. Wang, Y. Liu, L. Liu, X. Wang, N. Luo, L. Li, Clinical outcomes in 55 patients with severe acute respiratory syndrome coronavirus 2 who were asymptomatic at hospital admission in Shenzhen, China. J. Infect. Dis. 221(11), 1770-1774 (2020). https://doi.org/10.1093/infdis/jiaa119
56. S. Yan, X. Song, F. Lin, H. Zhu, X. Wang, M. Li, J. Ruan, C. Lin, X. Liu, Q. Wu, Z. Luo, W. Fu, S. Chen, Y. Yuan, S. Liu, J. Yao, C. Lv, Clinical characteristics of coronavirus disease 2019 in Hainan, China. medRxiv (2020), https://doi.org/10.1101/2020.03. 19.20038539.

57. J.J. Zhang, X. Dong, Y.Y. Cao, Y.D. Yuan, Y.B. Yang, Y.Q. Yan, C.A. Akdis, Y.D. Gao, Clinical characteristics of 140 patients infected with SARS-CoV-2 in Wuhan, China. Allergy 75(7), 1730-1741 (2020). https://doi.org/10.1111/all.14238

58. T.I. Hariyanto, A. Kurniawan, Thyroid disease is associated with severe coronavirus disease 2019 (COVID-19) infection. Diabetes Metab. Syndr. 14(5), 1429-1430 (2020). https://doi.org/10.1016/j. dsx.2020.07.044

59. M.D.M. Montesinos, C.G. Pellizas, Thyroid hormone action on innate immunity. Front Endocrinol. (Lausanne) 10, 350 (2019). https://doi.org/10.3389/fendo.2019.00350

60. J.L. McKechnie, C.A. Blish, The innate immune system: fighting on the front lines or fanning the flames of COVID-19? Cell Host Microbe 27(6), 863-869 (2020). https://doi.org/10.1016/j.chom. 2020.05.009

61. N. Figueroa-Vega, M. Alfonso-Pérez, I. Benedicto, F. SánchezMadrid, R. González-Amaro, M. Marazuela, Increased circulating pro-inflammatory cytokines and Th17 lymphocytes in Hashimoto's thyroiditis. J. Clin. Endocrinol. Metab. 95(2), 953-962 (2010). https://doi.org/10.1210/jc.2009-1719

62. L.F. Lv, H.Y. Jia, H.F. Zhang, Y.X. Hu, Expression level and clinical significance of IL-2, IL-6 and TGF- $\beta$ in elderly patients with goiter and hyperthyroidism. Eur. Rev. Med. Pharmacol. Sci. 21(20), 4680-4686 (2017)

63. Z. Yang, J. Liu, Y. Zhou, X. Zhao, Q. Zhao, J. Liu, The effect of corticosteroid treatment on patients with coronavirus infection: a systematic review and meta-analysis. J. Infect. 81(1), e13-e20 (2020). https://doi.org/10.1016/j.jinf.2020.03.062

64. V. Saferding, S. Blüml, Innate immunity as the trigger of systemic autoimmune diseases. J. Autoimmun. 110, 102382 (2020). https:// doi.org/10.1016/j.jaut.2019.102382

65. R. El Sabbagh, N.S. Azar, A.A. Eid, S.T. Azar, Thyroid dysfunctions due to immune checkpoint inhibitors: a review. Int J. Gen. Med 13, 1003-1009 (2020). https://doi.org/10.2147/IJGM. S261433

66. J.T. Ruiz, L. Luján, M. Blank, Y. Shoenfeld, Adjuvants- and vaccines-induced autoimmunity: animal models. Immunol. Res $\mathbf{6 5}$ (1), 55-65 (2017). https://doi.org/10.1007/s12026-016-8819-5

67. O. Vera-Lastra, A. Ordinola Navarro, M. P. Cruz Domiguez, G. Medina, T. I. Sánchez Valadez, L. J. Jara, Two cases of Graves' disease following SARS-CoV-2 vaccination: an autoimmune/ inflammatory syndrome induced by adjuvants. Thyroid. (2021). https://doi.org/10.1089/thy.2021.0142.

68. L.H. Garvey, S. Nasser, Anaphylaxis to the first COVID-19 vaccine: is polyethylene glycol (PEG) the culprit? Br. J. Anaesth. 126(3), e106-e108 (2021). https://doi.org/10.1016/j.bja.2020.12. 020

69. A. Brancatella, N. Viola, S. Brogioni, L. Montanelli, C. Sardella, P. Vitti, C. Marcocci, I. Lupi, F. Latrofa, Graves' disease induced by immune checkpoint inhibitors: a case report and review of the literature. Eur. Thyroid J. 8(4), 192-195 (2019). https://doi.org/10. $1159 / 000501824$ 